Психолого-педагогічні проблеми становлення сучасного фахівця Випуск 2018

УДК 616.33-006.6-06-089001.3107089.819

DOI 10.26697/9786177089017.2018.67

(C) Бойко В. В., Мирошниченко Д. А., Лавриненко А. С., 2018 Бойко Валерий Владимирович

Харьковский национальный медицинский университет,

ГУ «Институт общей и неотложной хирургии

им. В. Т. Зайцева НАМН Украины»

Мирошниченко Дмитрий Алексеевич

Харьковский национальный медицинский университет

Лавриненко Артем Сергеевич

Харьковский национальный медицинский университет

\title{
ИСПОЛЬЗОВАНИЕ ЭНДОВАСКУЛЯРНЫХ МЕТОДОВ У БОЛЬНЫХ С ЗАКРЫТОЙ ТРАВМОЙ ЖИВОТА
}

Введение. Одним из актуальных и социально значимых вопросов ургентной хирургической помощчи является травма органов брюшной полости. Учитывая возможности современной хирургии и опыт применения эндоваскулярных методов диагностики и лечения при кровотечениях желудочно-кишечного тракта, нами рассмотрена целесообразность использования данных методов при закрытой травме живота с повреждением сосудов брыжейки. Целью исследования была оценка возможности применения эндоваскулярных методов диагностики $и$ лечения пациентов $c$ повреждениями брыжейки при закрытой травме живота. Методы. В ГУ «Институт общей и неотложной хирургии им. В. Т. Зайщева НАМН Украины» $с$ 2010 по 2017 г2. на лечении находилось 96 пачиентов с изолированной травмой ЖКТ и брыжейки. Все пострадавшие были разделены на две группь: I-я группа - 53 пострадавших (2010-2014 гг.), которым применялись традиционные методы лечения; II-я группа - 43 пострадавших (2014-2017 г2.), которым применялись миниинвазивные методы лечения. Результать. Больным с нестабильной гемодинамикой лечение и обследование проводилось в условиях операчионной. Первым этапом хирургического лечения: $y$ пострадавших I-й группь в сомнительных случаях повреждений органов брюшной полости выполнялся лапарочентез $(n=29), \quad a$ пациентам II-й группь выполнялась диагностическая лапароскопия $(n=27)$, которая в последуюшем переходила в лечебную лапароскопию в случае вылвления гемоперитонеума объемом до 500 мл и без активного продолжающегося кровотечения. При выявлении гемоперитонеума более 500 мл и активного кровотечения проводилась конверсия. Выводы. Использование лапароскопического ушивания ран желудочно-кишечного тракта, ревизия и дренирование гематомы 


\section{Збірник наукових статей}

брыжейки, а также использование эндоваскулярной диагностики и гемостаза позволило снизить послеоперационные осложнения на 7,7\%, а средний койко-день на 3 дня.

Ключевые слова: повреждение брыжейки, лапароскопия, эндоваскулярный гемостаз.

Введение. Одним из актуальных и социально значимых вопросов ургентной хирургической помощи является травма органов брюшной полости $[1 ; 2 ; 5]$, при этом помощь пострадавшим с повреждением живота в настоящее время сводится к экстренной лапаротомии. Хирургические операции рассматриваются и как диагностическая манипуляция, и как доступ для коррекции повреждений органов [3;5;6]. По мнению ряда авторов, закрытая травма живота (ЗТЖ) в $37 \%$ случаев не сопровождаются массивными повреждениями органов брюшной полости $[1 ; 5 ; 6 ; 8 ; 11]$. В мировой практике, несмотря на более чем 30-ти летний опыт применения лапароскопических технологий лечения хирургических заболеваний, до сих пор дискутируются вопросы о возможном использовании лечебной лапароскопии и адекватности ревизии органов брюшной полости при абдоминальной травме $[1 ; 5 ; 6 ; 8 ; 10]$. Значение лапароскопии в диагностике ЗТЖ подчеркивают многие авторы [2-4; $8-10 ; 12 ; 13]$.

Учитывая возможности современной хирургии и опыт применения эндоваскулярных методов диагностики и лечения при кровотечениях желудочно-кишечного тракта (ЖКТ), нами рассмотрена целесообразность использования данных методов при ЗТЖ с повреждением сосудов брыжейки.

Цель исследования - оценить возможности применения эндоваскулярных методов диагностики и лечения пациентов с повреждениями брыжейки при ЗТЖ.

Материалы и методы. В ГУ «Институт общей и неотложной хирургии им. В. Т. Зайцева НАМН Украины» с 2010 по 2017 гг. на лечении находилось 96 пациентов с изолированной травмой ЖКТ и брыжейки. Все пострадавшие были разделены на две группы: I-я группа - 53 пострадавших (2010-2014 гг.), которым применялись традиционные методы лечения; II-я группа - 43 пострадавших (20142017 гг.), которым применялись миниинвазивные методы лечения. По полу и возрасту в обеих группах пациенты распределились следующим образом: мужчин было 83, женщин - 13; средний возраст пострадавших составил $31 \pm 5$ лет. По характеру получения травмы пациенты распределились следующим образом: в результате драки - 46 человек (I-я группа $\mathrm{n}=27$, II-я группа $\mathrm{n}=19$ ), пострадавшие в результате ДТП - 35 человек (I-я группа $\mathrm{n}=17$, II-я группа $\mathrm{n}=18$ ), падение при 
Психолого-педагогічні проблеми становлення сучасного фахівця Випуск 2018

ходьбе - 13 человек (I-я группа n=7, II-я группа $\mathrm{n}=6$ ), кататравма -2 пациента. Основная масса пациентов, как в I-й группе $(n=27)$, так и II-й группе $(\mathrm{n}=33)$ поступили в первый час с момента получения травмы; до 6 часов в I-й группе - 15 пострадавших, во II-й группе - 8 пострадавших; свыше 6 часов в I-й группе - 11 пострадавший, во II-й группе - 2 пациента.

Анатомическая локализация травмы и гематом у пострадавших в обеих группах представлена в таблице 1. Из представленной таблицы видно, что наиболее часто в обеих группах встречалось повреждение толстого кишечника и его брыжейки 47,9\%, на втором месте повреждение тонкой кишки $39,57 \%$ и на последнем месте изолированные повреждения брыжейки 12,53\%.

Таблица 1. Локализация повреждений ЖКТ.

\begin{tabular}{|c|c|c|c|c|c|}
\hline \multirow{2}{*}{\multicolumn{2}{|c|}{$\begin{array}{c}\text { Локализация поврежденного } \\
\text { отдела ЖКТ }\end{array}$}} & \multicolumn{2}{|c|}{$\begin{array}{c}\text { Группа } \\
\text { пострадавших }\end{array}$} & \multicolumn{2}{|c|}{ Всего } \\
\hline & & $\begin{array}{c}\mathrm{I}-я \\
\text { группа }\end{array}$ & $\begin{array}{c}\text { II-я } \\
\text { группа }\end{array}$ & Абс. & $\%$ \\
\hline Тощая кишка & & 8 & 7 & 15 & 15,62 \\
\hline Подвздошная ки & ишка & 12 & 11 & 23 & 23,95 \\
\hline Правые отделы & толстой кишки & 8 & 9 & 17 & 17,70 \\
\hline Поперечно-обод & дочная кишка & 4 & 4 & 8 & 8,33 \\
\hline Левые отделы тс & олстой кишки & 5 & 7 & 12 & 12,50 \\
\hline Сигмовидная ки & ишка & 4 & 5 & 9 & 9,37 \\
\hline $\begin{array}{l}\text { Изолированные } \\
\text { брыжейки }\end{array}$ & гематомы & 4 & 8 & 12 & 12,53 \\
\hline Всего & Абс. & 53 & 43 & 96 & - \\
\hline & $\%$ & 55,20 & 44,80 & - & 100,00 \\
\hline
\end{tabular}

У 3 пациентов $(3,1 \%)$ из основной группы эндовакулярные вмешательства были выполнены в катетерной лаборатории на ангиографическом аппарате Phillips «Integris Allura 12 С» (Голландия). Ангиографию выполняли из бедренного доступа по методике Сельдингера (1953 г.). В качестве эмболизирующего материала использовали металлические спирали типа Гиантурко. После проведения ангиографического исследования и эндоваскулярного вмешательства катетер с интродьюсером извлекали из артерии, после чего в течение 15-30 мин проводился гемостаз мануальным способом, на место пункции накладывалась асептическая давящая повязка, либо гемостаз достигался наложением гемостатической губки ExoSeal. Больным назначался строгий постельный режим на 12 часов. Давящая повязка снималась не ранее, чем через 16-18 ч после проведения вмешательства. 
Збірник наукових статей

Всем госпитализированным больным проводились противошоковые мероприятия направленные на стабилизацию гемодинамических показателей в условиях палаты интенсивной терапии профильного отделения. Одновременно проводились диагностические методы с целью определения поражения внутренних органов (паренхиматозных или полых), источника и наличия продолжающегося кровотечения. Исследования включали: забор крови, рентгенографию органов грудной и брюшной полостей, УЗИ.

Результаты. Для выбора тактики лечения больных (лапаротомия или миниинвазивные методы) была использована бальная шкала [7]. Если общая сумма балов составляла до 10 больному было показано проведение миниинвазивных манипуляций. При сумме балов от 10 до 15 применялись миниинвазивные или традиционные методы лечения. При сумме более 15 балов - показана лапаротомия.

Больным c нестабильной гемодинамикой лечение и обследование проводилось в условиях операционной. Первым этапом хирургического лечения: у пострадавших І-й группы в сомнительных случаях повреждений органов брюшной полости выполнялся лапароцентез [8] (n=29), а пациентам II-й группы выполнялась диагностическая лапароскопия $(\mathrm{n}=27)$, которая в последующем переходила в лечебную лапароскопию в случае выявления гемоперитонеума объемом до 500 мл и без активного продолжающегося кровотечения. При выявлении гемоперитонеума более 500 мл и активного кровотечения проводилась конверсия.

При условиях стабильной гемодинамики больным проводилась компьютерная томография с внутривенным введением контрастных веществ (рисунок 1, 2).

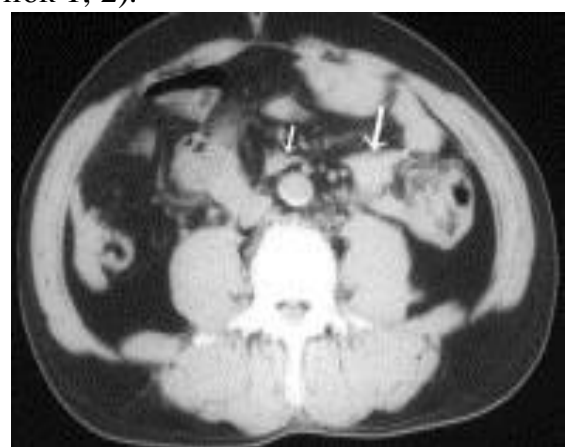

Рисунок 1. 62-летний мужчина с гематомой брыжейки. По данням КТ - типичная гематома треугольной формы (стрелки) вдоль брыжейки. Гемоперитонеум. Интра операционно с очаговой гематомой был обнаружен разрыв брыжейки. 


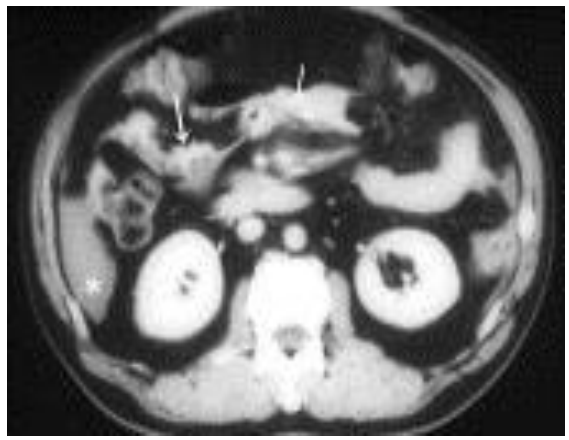

Рисунок 2. 50-летний мужчина с активным кровотечением из брыжейки тонкой кишки. КТ показывает экстравазацию контрастного вещества в брыжейку кишки (стрелки), и наличие гемоперитонеума. Интраоперационно пациенту требовалась перевязка активно кровоточащих сосудов и резекция нежизнеспособной тощей кишки.

\section{У 3 больных $(3,1 \%)$ II группы в тяжелом состоянии с травматическим шоком 1-2 степени было произведено ангиографическое исследования мезентериальных сосудов на факт выявления гематом брыжейки. Оценивалось наличием экстравазации контрастного вещества между листками брыжейки (рисунок 3 ).}

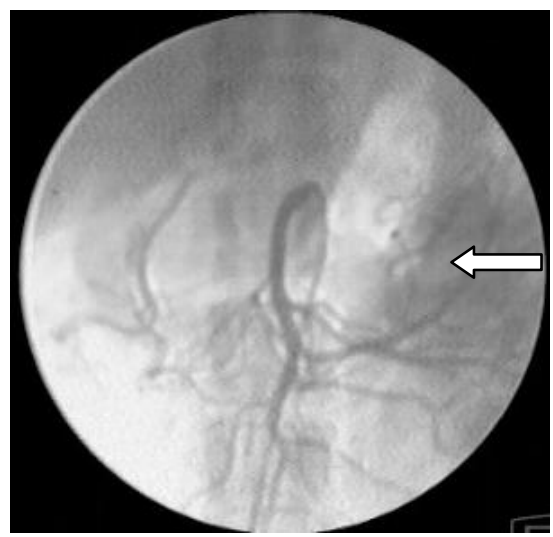

Рисунок 3. Верхняя мезентерикография больного Б., 47 лет, с закрытой травмой живота, гематомой брыжейки толстой кишки. Определяется экстравазация контрастного вещества (стрелка) в бассейне нижней панкреатодуоденальной артерии. 


\section{Збірник наукових статей}

У 1 (1,04\%) больного из трех было выявлено продолжающееся кровотечение (увеличение гематомы в объеме до 50 мл) (рисунок 4), что потребовало активной тактики, перехода из диагностического метода в лечебный (эмболизации поврежденного сосуда), как окончательный гемостаз, не потребовавший открытого хирургического лечения (рисунок 5).

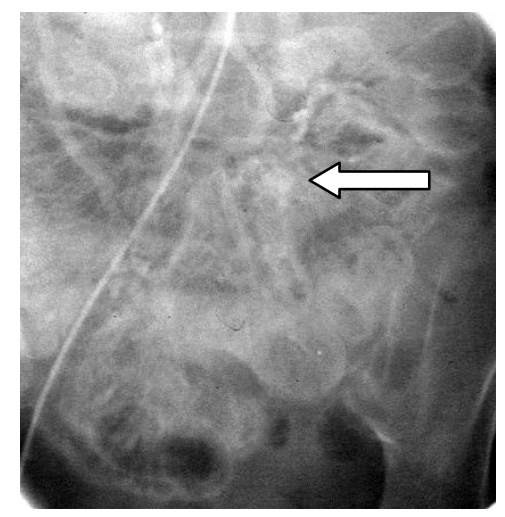

Рисунок 4. Верхняя мезентерикография больного Н., 38 лет, с закрытой травмой живота, гематомой брыжейки тонкой кишки. Определяется экстравазация контрастного вещества (стрелка) в бассейне aa.ileales.

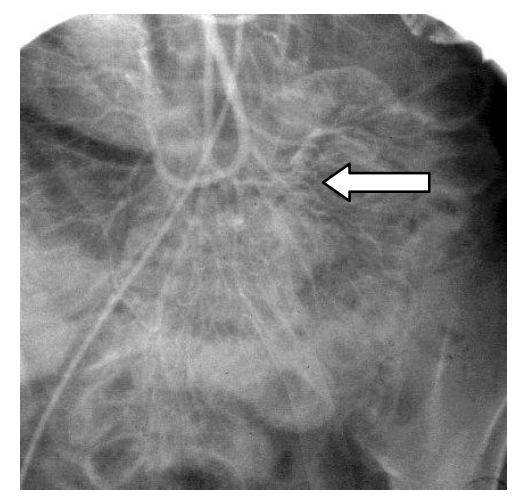

Рисунок 5. Контрольная верхняя мезентерикография больного Н., 38 лет, после эмболизации ветвей aa.ileales. Определяется спираль типа Гиантурко в просвете сосуда (стрелка), экстравазации нет. 
Психолого-педагогічні проблеми становлення сучасного фахівця Випуск 2018

В послеоперационном периоде больным проводилось мониторирование состояния на предмет рецидива кровотечения из поврежденных сосудов. В программу лечения включали профилактическое введение антибактериальных, нестероидных противовоспалительных препаратов. Динамический контроль УЗИ на 1-е, 3-и, 7-е сутки показал отсутствие нарастание гематом в объеме, а также их вторичного инфицирования, в результате чего послеоперационные осложнения снизились на 7,7\%, а средний койкодень сократился на 3 дня в сравнении с больными I-й группы.

В отдаленном послеоперационном периоде через 1 месяц при проведении УЗИ и КТ после эмболизации было выявлено регресс гематомы в размерах до 70\%, а через 2-3 месяца - полный регресс гематом.

Выводы. 1. Пострадавшим с ЗТЖ необходимо применять балльную оценку возможности использования миниинвазивных методов лечения. 2. Использование балльной системы оценки позволило у пострадавших II группы с изолированной травмой ЖКТ применить миниинвазивные методы лечения, а у 3 больных $(3,1 \%)$ этой группы - ангиографическое исследование мезентериальных сосудов, при этом у 1 больного (1,04\%) это явилось заключительным этапом лечения. 3. Пострадавшим с изолированной травмой ЖКТ, у которых сумма баллов не превышает 10 и объем $<50$ мл, необходимо применять миниинвазивные методы, такие как ангиография с возможной эмболизацией поврежденного сосуда. 4. Применение ангиографического лечения изолированной травмы ЖКТ позволило значительно сократить период трудовой и социальной реабилитации у пострадавших II-й группы: послеоперационные осложнения снизились на 7,7\%, а средний койко-день сократился на 3 дня в сравнении с пациентами I-й группы. 5. Считаем, что есть все основания продолжать исследования в данном направлении: плодотворном - в теоретическом, и важном - в практическом отношении.

\section{Литература}

1. Абакумов М. М. Повреждения живота при сочетанной травме / М. М. Абакумов, Н. В. Лебедев, В. И. Малярчук. - М. : Медицина, 2005. - 175 c.

2. Бойко В. В. Закрытая травма живота / В. В. Бойко, М. Г. Кононенко. - Х., 2008. - 528 с.

3. Ермолов А. С. Видеолапароскопия при открытых повреждениях органов брюшной полости / А. С. Ермолов, П. А. Ярцев, А. А. Гуляев // Эндоскопическая хирургия. - 2006. - № 6. - С. 32-35. 


\section{Збірник наукових статей}

4. Лапароскопія у невідкладній хірургії та гінекології / В. В. Бойко, Ю. Б. Григоров, В. Г. Дуденко [та ін.]. - Х. : Торнадо, 2002. $-174 \mathrm{c}$.

5. Меликян А. Р. Роль лапароскопии в диагностике и лечении ножевых и огнестрельных ранений живота в мирное и военное время / А. Р. Меликян, Г. 3. Балаян // Материалы VII съезда Российского общества эндоскопических хирургов, 16-20 февраля 2004 г. - М., 2004. - C. 91-92.

6. Миниинвазивные и органосберегающие операции при травмах живота / В. М. Тимербулатов, А. Г. Хасанов, Р. Р. Фаязов [и др.] // Хирургия. - 2008. - № 4. - С. 29-32.

7. Патент на корисну модель 75329, МПК А61В 17/ 00. Спосіб визначення показань до лапароскопії або лапаротомії при відкритій травмі органів черевною порожнини / Пєєв С. Б.; заявник та патентовласник Пєєв Станіслав Борисович - №u2012 06416; заявл. 28.05.12; опубл. 26.11.12, Бюл. № 22.

8. Патент на корисну модель 121717, МПК: А61В 17/ 34, А61В 8/ 12, G01N 33/ 48. Спосіб діагностичного лапароцентезу / Бойко В. В., Лавріненко А. С., Арсеній I. І.; заявник та патентовласник Державна Установа «Інститут Загальної та Невдкладної Хірургї ім. В. Т. Зайцева Нацональної Академії Медичних Наук України» - №u2017 07001; заявл. 03.07.17; опубл. 11.12.2017, Бюл. № 23.

9. Роль видеолапароскопии в диагностике и лечении абдоминальной травмы / П. А. Ярцев, А. А. Гуляев, Г. В. Пахомова [и др.] // Эндоскопическая хирургия. - 2008. - № 2. - С. 28-31.

\section{0. Хирургия абдоминальных повреждений}

В. М. Тимербулатов, А. Г. Хасанов, Р. Р. Фаязов [и МЕДпресс-информ, 2005. - 256 с.

11. Diagnosis of significant abdominal trauma after road traffic accidents: Preliminary results of a multicenter clinical trial comparing minilaparoscopy with peritoneal lavage / A. Cuschieri, T. Hennessy, R. Stephens, G. Berci // Ann R Coll Surg Engl. - 1988.- Vol. 70. - P. 153155.

12. Diagnostic and therapeutic laparoscopy for trauma: a technique of safe and systematic exploration / P. J. Gorecki, D. Cottam, L. D. Angus, G. W. Shaftan // Surg. Laparosc. Endosc. Percutan. Tech. - 2007. - Vol. 12 (3). - P. 195-198.

13. The use of laparoscopy in the diagnosis and treatment of blunt and penetrating abdominal injuries, 10-year experience at a level 1 trauma center / J. J. Johnson, T. Garwe, A. R. Raines et al. // Am J Surg. - 2013. Vol. 205. - P. 317-321. 
Психолого-педагогічні проблеми становлення сучасного фахівця Випуск 2018

14. Negative laparotomy in abdominal gunshot wounds: Potential impact of laparoscopy / J. L. Sosa, M. Baker, I. Puente et al. // J Trauma. 1995. - Vol. 38. - P. 194-197.

\section{Валерій Бойко, Дмитро Мирошниченко, Артем Лавриненко. Використання ендоваскулярних методів у хворих із закритою травмою живота.}

Bступ. Одним з актуальних і соџіально значущих питань ургентної хірургічної допомоги є травма органів черевної порожнини. 3 огляду на можливості сучасної хірургії $i$ досвід застосування ендоваскулярних методів діагностики $i$ лікування при кровотечах шлунково-кишкового тракту нами розглянута доцільність використання даних методів при закритій травмі живота $з$ пошкодженням судин брижі. Метою дослідження була оиінка можливості застосування ендоваскулярних методів діагностики $i$ лікування пацієнтів з ушкодженнями брижі при закритій травмі живота. Методи. У ДУ «Інститут загальної та невідкладної хірургії ім. В. Т. Зайцева НАМН Украӥни» з 2010 по 2017 рр. на лікуванні знаходилось 96 паиієнтів з ізольованою травмою ШКТ $i$ брижі. Всі постраждалі були розділені на дві групи: I-а група 53 постраждалих (2010-2014 рр.), яким застосовувалися традиційні методи лікування; II-а група 43 постраждалих (2014-2017 рр.), яким застосовувалися мініінвазивні методи лікування. Результати. Хворим з нестабільною гемодинамікою лікування $i$ обстеження проводилося в умовах операційної. Першим етапом хірургічного лікування: у постраждалих I-ї групи в сумнівних випадках пошкоджень органів черевної порожсини виконувався лапароцентез $(n=29)$, а паџієнтам II-ї групи виконувалася діагностична лапароскопія $(n=27)$, яка в подальшому переходила в лікувальну лапароскопію в разі виявлення гемоперитонеума об'смом до 500 мл $і$ без активної триваючої кровотечі. При виявленні гемоперитонеума більше 500 мл $і$ активної кровотечі проводилась конверсія. Висновки. Використання лапароскопічного ушивання ран шлунково-кишкового тракту, ревізія $i$ дренування гематоми брижі, а також використання ендоваскулярної діагностики та гемостазу дозволило знизити післяоперащійні ускладнення на 7,7\%, а середній ліжко-день на 3 дні.

Ключові слова: пошкодження брижі, лапароскопія, ендоваскулярний гемостаз.

Valeriy Boyko, Dmitry Myroshnychenko, Artyom Lavrinenko. Use of endovascular methods in patients with closed injury of abdomen. Introduction. One of the urgent and socially significant issues of urgent surgical care is injury of the abdominal cavity. Considering the possibilities 
of modern surgery and the experience of applying endovascular methods of diagnosis and treatment in bleeding gastrointestinal tract, we considered the expediency of using these methods with closed abdominal trauma with damage to the mesentery vessels. The purpose of the study was to evaluate the possibility of using endovascular methods for diagnosis and treatment of patients with mesentery injuries with closed abdominal trauma. Methods. At «V.T. Zaytsev Institute of General and Emergency Surgery of NAMS of Ukraine» from 2010 till 2017 years 96 patients with isolated intestinal tract and mesentery were on treatment. All the victims were divided into two groups: 1st group of 53 victims (2010-2014), who used traditional methods of treatment; The second group of 43 victims (2017-2014), who used the minimally invasive methods of treatment. Results. Patients with unstable hemodynamics treated and examined in the operating conditions. The first stage of surgical treatment: in the cases of doubtful cases of abdominal cavity injuries, the patients of the 1 st group performed laparocentesis $(n=29)$, and the patients of the 2nd group performed diagnostic laparoscopy ( $n=27)$, which later went into therapeutic laparoscopy in case detection of hemoperitoneum volume up to $500 \mathrm{ml}$ and without active bleeding. At detection of hemoperitoneum more than $500 \mathrm{ml}$ and active bleeding a conversion was made. Conclusions The use of laparoscopic wounding of the wounds of the gastrointestinal tract, audit and drainage of hematoma, as well as the use of endovascular diagnosis and hemostasis, allowed to reduce postoperative complications by 7,7\%, and the average bed - day for 3 days.

Keywords: blunt abdominal trauma, damage of mesenteric arteries, laparoscopy, endovascular hemostasis, bleeding.

Стаття надійшла до редакційної колегії 04.05.2018

Прийнято до друку 07.05.2018

\section{Інформація про авторів:}

Бойко Валерий Владимирович - доктор медицинских наук, профессор, член-корреспондент НАМН Украины, директор, ГУ «Институт общей и неотложной хирургии им. В. Т. Зайцева НАМН Украины»; заведующий кафедрой хирургии № 1, Харьковский национальный медицинский университет.

Мирошниченко Дмитрий Алексеевич - кандидат медицинских наук, ассистент кафедры хирургии № 1, Харьковский национальный медицинский университет.

Лавриненко Артем Сергеевич - ассистент кафедры хирургии № 1, Харьковский национальный медицинский университет. 